\title{
A cost comparison of more and less nutritious food choices in US supermarkets
}

\author{
David L Katz ${ }^{1, *}$, Kim Doughty ${ }^{1}$, Valentine Nijke ${ }^{1}$, Judith A Treu' ${ }^{1}$, \\ Jesse Reynolds ${ }^{1}$, Jennifer Walker ${ }^{2}$, Erica Smith ${ }^{2}$ and Catherine Katz ${ }^{1}$ \\ 'Yale-Griffin Prevention Research Center, Yale University School of Medicine, Griffin Hospital, 130 Division \\ Street, Derby, CT 06418, USA: ${ }^{2}$ Independence School District, Independence, MO, USA
}

Submitted 22 March 2010: Accepted 12 January 2011: First published online 28 February 2011

\begin{abstract}
Objective: The present study directly compared prices of more and less nutritious foods within given categories in US supermarkets.

Design: Foods selected from six supermarkets in Jackson County were categorized using the five criteria of the Nutrition Detectives ${ }^{\mathrm{TM}}$ (ND) programme and an item-to-item cost comparison was made using posted prices. The nutritional quality of foods was distinguished using the clues of the ND nutrition education programme for elementary-school children and validated using the Overall Nutritional Quality Index.

Setting: Supermarkets in Jackson County, MO, USA.

Subjects: Not applicable.

Results: The average price of the item for more nutritious foods did not differ significantly from that of less nutritious foods overall (\$US $2 \cdot 89$ (SD \$US 0.74) $v$. $\$$ US $2 \cdot 85$ (SD $\$ 0 \cdot 68$ ), $P=0 \cdot 76$ ). More nutritious breads cost more than less nutritious breads ( $\$$ US $3 \cdot 36$ (sD $\$$ US $0 \cdot 28$ ) v. $\$$ US 2.56 (sD $\$$ US $0 \cdot 80, P=0 \cdot 03$ ), whereas more nutritious cereals (\$US $2 \cdot 46$ (SD \$US $0 \cdot 69$ ) v. \$US $3 \cdot 50$ (SD \$US $0 \cdot 30$ ), $P<0 \cdot 01$ ) and cookies (\$US $2 \cdot 76$ (SD \$US 0.50) v. \$US $3 \cdot 40$ (SD \$US0 28 ), $P<0 \cdot 01$ ) cost less.

Conclusions: Our findings indicate that it is possible to choose more nutritious foods within many common categories without spending more money and suggest that making small improvements in dietary choices does not invariably cost more.
\end{abstract}

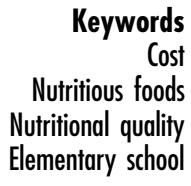

Diet-related conditions such as obesity, heart disease and diabetes are significant threats to public health and to the economy in the $\mathrm{USA}^{(1-9)}$. One of the most significant contributors to obesity is food intake ${ }^{(1)}$. With respect to weight management, energy is most salient. However, there is evidence that other dietary variables, such as glycaemic index or glycaemic load, may also impact weight $^{(10,11)}$. Increased intake of dietary fibre has been associated with a reduction in visceral adipose tissue specifically $^{(12)}$. Furthermore, diet has been found to be a major determinant of health outcomes ${ }^{(13-15)}$ and the quality of the diet a powerful predictor of chronic disease risk $^{(16-23)}$. Adoption of dietary patterns more consistent with recommendations could contribute to significant reductions in the burden of chronic disease ${ }^{(24)}$.

One commonly cited barrier to healthy eating is the high cost of nutritious foods compared with foods with less nutritional value. The notion that economics play an important role in eating behaviour is supported by studies that have associated obesity and less-healthy dietary patterns with low income or socio-economic status ${ }^{(25,26)}$. In addition, low-energy-dense foods, which tend to be more nutritious and less likely to lead to weight gain, typically cost more than high-energy-dense foods, which usually contain fewer nutrients ${ }^{(27-29)}$.

Nutrition Detectives $^{\text {TM }}$ (ND) is a school-based nutrition education programme that teaches elementary-school children how to make better food choices by reading food labels ${ }^{(30,31)}$. The programme uses five clues to help children make those choices. Foods that meet the nutritional criteria of the programme are called 'Clued-in', whereas those that do not are called 'Clue-less'. A 2-year pilot study of the programme in elementary schools in the Independence, Missouri, school district found that nutritional knowledge improved significantly both for students in the intervention group and for their parents. Although the programme may help families to identify nutritious foods, it will not be sufficient for behavioural change if these foods are more expensive than less nutritious foods.

The purpose of the present study was to compare the cost of more nutritious and less nutritious foods, as identified by the criteria taught to participants in the ND programme, in several different food categories. This comparison was made to determine whether it is possible 
for individuals to apply the knowledge gained in this nutrition education curriculum to purchase foods of higher nutritional value within food categories without increasing their food costs.

\section{Experimental methods}

\section{Nutrition Detectives ${ }^{\text {TM }}$ programme}

This cost-comparison study was conducted as part of the ND school-based nutrition education programme targeted towards elementary-school children ${ }^{(32)}$. The goals of the programme were: (i) to teach children to make healthy food choices and detect marketing deceptions; (ii) to give students the opportunity to practise what they have learned; and (iii) to empower children to share their 'detective skills' with other family members. ND was originally developed by D.K. and C.K. The programme provides five clues in order to make healthy food choices on the basis of the 'Nutrition Facts' labels and ingredient lists on food packages. The five clues are: (i) do not be fooled by the front of the box; instead, rely on the Nutrition Facts panel and ingredient list for the truth; (ii) the first ingredient is always the biggest and thus an important consideration; (iii) generally avoid foods that contain partially hydrogenated oil, high-fructose corn syrup or artificial ingredients; (iv) generally avoid foods with a long ingredient list; and (v) fibre is your friend; hence, choose grain products that say 'whole' grain and provide $\geq 2 \mathrm{~g}$ of fibre per $418 \mathrm{~kJ}$ ( $100 \mathrm{kcal})$. Foods that satisfy these criteria are considered to be 'Clued-in' (more nutritious) choices. Foods that do not meet these criteria are 'Clue-less' (less nutritious). The programme is delivered in one or more sessions for a total of $90 \mathrm{~min}$ of classroom instruction time. Hands-on activities for practising what is learned are also included in the curriculum ${ }^{(30,31)}$.

\section{Food selection}

A research assistant was trained in the ND programme and instructed to use the five clues of the programme to select one or more representative items meeting, or failing to meet, the requirements of the 'five clues' in each of eight food categories commonly used when teaching the programme. The research assistant brought a checklist of criteria to the supermarket to select more and less nutritious items consistent with the programme. An attempt was made to use popular items that are widely sold and to identify products within a given category that were very comparable to one another. Since the sampling was a test of principle, it was selective rather than systematic. The price of each item was standardized per $100 \mathrm{~g}$ by multiplying the price of the food item by 100 and then dividing by the total weight of the item. These data were obtained from the Nutrition Facts panel of each item used in the study.

More nutritious and less nutritious foods in eight food categories were selected for price comparison. The categories included bread, cereal bars, cereal, chips, cookies, crackers, juices and peanut butter. These categories were selected because they were representative of the 'middle aisles' of most supermarkets in which packaged foods predominate and are used in the ND curriculum; after an instructive session, children were asked to practise their label-reading skills by identifying more and less nutritious items in these food categories. Items were selected from six chain grocery stores that were accessible to the research assistant.

Foods were categorized as more nutritious or less nutritious on the basis of the ND clues relevant to their food category. For an item to be considered more nutritious, it was subjectively determined to not have excessive marketing-related claims or images on the front of the package; have an unhealthy ingredient such as sugar or white flour listed first; contain partially hydrogenated oil or high-fructose corn syrup; or have a long ingredient list relative to other items in that category. For grain-based products only, more nutritious foods also had to contain at least $2 \mathrm{~g}$ of fibre per serving.

To validate the ND selection criteria, more and less nutritious foods were also scored using the Overall Nutritional Quality Index (ONQI). The ONQI is a nutritional scoring system for foods, applied in the $\mathrm{NuVal}^{\mathrm{TM}}$ nutritional scoring system (www.nuval.com) that uses a scale of 1-100 to represent the overall nutritional quality. A multidisciplinary panel was convened to develop the ONQI. Twelve experts in such fields as nutritional epidemiology, food labelling, insulin metabolism, endocrinology and appetite control comprised the panel ${ }^{(32)}$. Dietary guidelines, existing nutritional scoring systems and other pertinent scientific literature were reviewed. An algorithm based on the overall nutritional quality was developed and tested. The ONQI algorithm incorporates over thirty entries representing both micro- and macronutrient properties of foods, as well as weighting coefficients representing epidemiological associations between nutrients and health outcomes. In content validity testing, ONQI rankings and expert panel rankings correlated highly $(R=0 \cdot 92 ; \quad P<0 \cdot 001)^{(33,34)}$. The algorithm has also been validated by significant correlations with the Healthy Eating Index $2005^{(35)}$. Findings from a large prospective cohort study indicate that intakes of foods with high ONQI scores are associated with reduced risks of CVD, diabetes and total mortality for men and women $^{(36)}$. The ONQI algorithm is used in the $\mathrm{NuVal}^{\mathrm{TM}}$ nutritional scoring system, currently active in 526 US supermarkets in eighteen states (www.nuval.com).

\section{Statistical analysis}

Descriptive statistics were used to describe the sample of products used in the study. To validate the ND criteria using the ONQI, the independent $t$ test was used to assess mean differences in ONQI scores between more and less nutritious foods. The independent $t$ test was also used to assess overall differences in price between more and less 
nutritious foods, as well as the difference between more and less nutritious products with respect to each food category in all dependent outcomes (ONQI, price and standardized price). Models incorporating independent variables (i.e. food category) testing for differences between more and less nutritious foods in terms of ONQI score, price and adjusted price were conducted using analysis of covariance. To assess the predictive ability of the ONQI on item price and standardized price, linear regression was used. Cohen's $d$ was calculated to assess the effect size for all outcome measures. Data were analysed using the Statistical Package for the Social Sciences statistical software package for Windows version $15 \cdot 0$ (SPSS Inc., Chicago, IL, USA). In all analyses, a two-tailed $\alpha$ of $<0.05$ was considered statistically significant. Results are expressed as mean and SD in text and tables.

\section{Results}

A total of sixty-three more nutritious and sixty-eight less nutritious foods were assessed, with a range of thirteen to eighteen foods compared within each food category. Of the 131 items included, $74 \cdot 8 \%$ were brand name products and $25 \cdot 2 \%$ were store brand items. Among more nutritious items, the proportions were $58.7 \%$ and $41 \cdot 3 \%$, respectively. Among less nutritious items, $89 \cdot 7 \%$ were brand names and $10 \cdot 3 \%$ were store brands. Examples of more nutritious items included Pepperidge Farm 100\% whole-wheat bread, Quaker Oat Co. Oatmeal Squares cereal, Kellogg's All-bran Multigrain crackers, Capri Sun All Natural 100\% juice and Smucker's natural peanut butter. Some less nutritious items included Wonder Classic bread, General Mills Lucky Charms cereal, Keebler Townhouse crackers, Capri Sun Roarin' Waters juice drink and Skippy peanut butter.
Within each category, selected items were similar in terms of characteristics unrelated to nutritional quality. In the chips category, potato chips and tortilla chips were represented in both the more and less nutritious groups. A variety of cookies were represented: butter cookies, chocolate chip, crème-filled and peanut butter cookies were included in both groups. More and less nutritious crackers were represented by wheat or grain crackers and cheese crackers. Juices and drinks were necessarily different because the more nutritious juices were all 100\% juice, whereas the less nutritious items contained little or no fruit juice. However, all were non-carbonated and fruit flavoured. The peanut butter category included highly similar products, with the exception of two items in the less nutritious group that also contained grape jelly. In the bread category, only white, wheat or multigrain breads were chosen. Each group of cereal bars included soft and crunchy granola bars and bars made with other types of cereal. The more nutritious group also included a trail mix bar and a chocolate brownie flavoured children's snack bar. A complete list of all selected items is on file (Yale Prevention Research Center).

\section{Overall Nutritional Quality Index score of the item}

Between-group ONQI scores did not differ significantly for bread $(P=0 \cdot 68)$, cookies $(P=0 \cdot 12)$ or juices $(P=0 \cdot 06)$, although in each case the mean score was higher for the 'more nutritious' group; for the remaining categories (cereal bars, cereal, chips, crackers and peanut butter) more nutritious items had significantly higher ONQI scores $(P<0 \cdot 05$; Table 1$)$. Overall, the ONQI scores for more nutritious items used in the study were significantly higher than those of the less nutritious items $(P<0 \cdot 01)$.

Table 1 Summary of ONQI and price for the less and more nutritious foods

\begin{tabular}{|c|c|c|c|c|c|c|c|c|c|c|c|c|c|c|}
\hline \multirow[b]{2}{*}{ Item type } & \multirow[b]{2}{*}{ Type } & \multirow[b]{2}{*}{$n$} & \multicolumn{2}{|c|}{ ONQI } & \multirow[b]{2}{*}{$P$ value } & \multirow[b]{2}{*}{$d$} & \multicolumn{2}{|c|}{ Item price (\$US) } & \multirow[b]{2}{*}{$P$ value } & \multirow[b]{2}{*}{$d$} & \multicolumn{2}{|c|}{ Standard price (\$US) } & \multirow[b]{2}{*}{$P$ value } & \multirow[b]{2}{*}{$d$} \\
\hline & & & Mean & SD & & & Mean & SD & & & Mean & SD & & \\
\hline \multirow[t]{2}{*}{ Overall } & Less nutritious & 68 & $14 \cdot 7$ & $9 \cdot 3$ & $<0 \cdot 01$ & $1 \cdot 1$ & $2 \cdot 85$ & 0.68 & 0.76 & 0.0 & $0 \cdot 86$ & 0.78 & 0.92 & 0.0 \\
\hline & More nutritious & 63 & $24 \cdot 8$ & $9 \cdot 4$ & & & $2 \cdot 88$ & $0 \cdot 74$ & & & $0 \cdot 88$ & 0.50 & & \\
\hline \multirow[t]{2}{*}{ Bread } & Less nutritious & 8 & $27 \cdot 0$ & $5 \cdot 1$ & 0.68 & 0.2 & $2 \cdot 55$ & $0 \cdot 80$ & 0.03 & $1 \cdot 3$ & 0.38 & $0 \cdot 13$ & 0.04 & $1 \cdot 1$ \\
\hline & More nutritious & 9 & $27 \cdot 9$ & $3 \cdot 6$ & & & $3 \cdot 35$ & $0 \cdot 28$ & & & 0.49 & 0.04 & & \\
\hline \multirow[t]{2}{*}{ Cereal bars } & Less nutritious & 9 & $14 \cdot 3$ & $6 \cdot 1$ & $<0.01$ & $2 \cdot 3$ & $2 \cdot 81$ & 0.27 & $<0.01$ & $1 \cdot 6$ & $2 \cdot 07$ & 1.50 & $0 \cdot 32$ & $2 \cdot 9$ \\
\hline & More nutritious & 8 & $26 \cdot 5$ & $4 \cdot 4$ & & & $3 \cdot 20$ & $0 \cdot 22$ & & & $1 \cdot 55$ & 0.20 & & \\
\hline \multirow[t]{2}{*}{ Cereal } & Less nutritious & 9 & $20 \cdot 7$ & $5 \cdot 7$ & $<0.01$ & $1 \cdot 8$ & $3 \cdot 50$ & $0 \cdot 30$ & $<0.01$ & $1 \cdot 9$ & $0 \cdot 87$ & 0.23 & 0.02 & $1 \cdot 2$ \\
\hline & More nutritious & 9 & $29 \cdot 8$ & $4 \cdot 0$ & & & $2 \cdot 46$ & 0.69 & & & 0.59 & 0.22 & & \\
\hline \multirow[t]{2}{*}{ Chips } & Less nutritious & 9 & $14 \cdot 8$ & $10 \cdot 0$ & 0.01 & $1 \cdot 4$ & $2 \cdot 87$ & 0.79 & 0.06 & $1 \cdot 0$ & $1 \cdot 01$ & 0.27 & 0.48 & 0.3 \\
\hline & More nutritious & 8 & $25 \cdot 4$ & $2 \cdot 8$ & & & $2 \cdot 17$ & 0.55 & & & $0 \cdot 88$ & 0.46 & & \\
\hline \multirow[t]{2}{*}{ Cookies } & Less nutritious & 9 & $7 \cdot 6$ & $3 \cdot 7$ & $0 \cdot 12$ & $0 \cdot 8$ & $3 \cdot 40$ & 0.28 & $<0.01$ & $1 \cdot 6$ & 0.92 & 0.24 & 0.48 & 0.3 \\
\hline & More nutritious & 8 & $14 \cdot 5$ & $12 \cdot 0$ & & & $2 \cdot 75$ & 0.50 & & & $1 \cdot 04$ & 0.45 & & \\
\hline \multirow[t]{2}{*}{ Crackers } & Less nutritious & 9 & $14 \cdot 1$ & $8 \cdot 0$ & $<0.01$ & $2 \cdot 6$ & $2 \cdot 56$ & 0.92 & $0 \cdot 70$ & $0 \cdot 2$ & 0.84 & 0.33 & 0.03 & $1 \cdot 2$ \\
\hline & More nutritious & 8 & $29 \cdot 4$ & $2 \cdot 3$ & & & $2 \cdot 69$ & 0.36 & & & $1 \cdot 22$ & 0.30 & & \\
\hline \multirow{2}{*}{ Juices } & Less nutritious & 8 & 1.9 & $0 \cdot 8$ & 0.06 & $1 \cdot 2$ & $2 \cdot 54$ & 0.53 & $0 \cdot 14$ & 0.9 & $0 \cdot 12$ & 0.03 & $0 \cdot 22$ & 0.6 \\
\hline & More nutritious & 7 & $13 \cdot 9$ & $13 \cdot 6$ & & & 2.99 & 0.50 & & & 0.43 & 0.69 & & \\
\hline \multirow{2}{*}{ Peanut butter } & Less nutritious & 7 & $17 \cdot 6$ & $7 \cdot 0$ & 0.02 & $1 \cdot 5$ & $2 \cdot 36$ & $0 \cdot 32$ & 0.07 & $1 \cdot 3$ & 0.47 & 0.06 & 0.05 & $1 \cdot 4$ \\
\hline & More nutritious & 6 & $30 \cdot 5$ & $10 \cdot 2$ & & & $3 \cdot 66$ & $1 \cdot 39$ & & & $0 \cdot 80$ & 0.32 & & \\
\hline
\end{tabular}

ONQI, Overall Nutritional Quality Index. 
When controlling for food category, ONQI scores for more nutritious foods differed significantly from the ONQI scores of less nutritious items $\left(F_{(1,130)}=66 \cdot 61 ; P=0 \cdot 00\right)$. As a factor in the model, food category was a statistically significant contributor $\left(F_{(7,124)}=15 \cdot 51 ; P=0 \cdot 00\right)$. No significant interaction was found between clue type and food category in the model $\left(F_{(7,124)}=1 \cdot 70 ; P=0 \cdot 12\right)$.

\section{Item price}

The overall average item price between more nutritious foods and less nutritious foods did not differ significantly $(P=0 \cdot 76)$. With respect to food category, more nutritious breads were significantly more expensive than less nutritious breads $(P=0 \cdot 03)$, whereas more nutritious cereals $(P<0 \cdot 01)$, cereal bars $(P<0 \cdot 01)$ and cookies $(P<0 \cdot 01)$ were found to cost significantly less compared with their less nutritious counterparts. More nutritious chips were found to be cheaper than less nutritious chips but did not reach statistical significance $(P=0 \cdot 06)$. More nutritious peanut butter was more expensive on average, although this difference was also not statistically significant $(P=0 \cdot 07)$. There were no significant differences in price between more and less nutritious crackers $(P=0 \cdot 70)$ or juices $(P=0 \cdot 14$; Table 1$)$.

The average item price for more nutritious foods did not differ significantly from that of less nutritious items when controlling for food category $\left(F_{(1,130)}=0 \cdot 64\right.$; $P=0 \cdot 43)$. Interaction between clue type and food category was statistically significant $\left(F_{(7,124)}=7 \cdot 71 ; P=0 \cdot 00\right)$.

ONQI scores of food items used in the present study did not significantly predict the item price $\left(t_{(130)}=0 \cdot 67\right.$; $P=0.50)$.

\section{Standardized price}

The difference in the average overall standardized price between more nutritious foods and less nutritious foods was not statistically significant $(P=0 \cdot 92)$. More nutritious breads, crackers and peanut butter were significantly more expensive than their less nutritious counterparts $(P=0 \cdot 04,0.03$ and $0 \cdot 05$, respectively). On the other hand, more nutritious cereals cost significantly less than less nutritious cereals $(P=0 \cdot 02)$. The standardized price difference between more and less nutritious chips and cereal bars favoured the more nutritious items but did not reach significance $(P=0.48$ and $0 \cdot 32$, respectively). There were no significant differences in the price of cookies $(P=0 \cdot 48)$ or juices $(P=0 \cdot 22)$, despite higher average adjusted prices for the more nutritious items in each category (Table 1).

More nutritious foods did not significantly differ from less nutritious items in standardized price when controlling for food category $\left(F_{(1,130)}=0 \cdot 23 ; P=0 \cdot 63\right)$. However, food category significantly contributed to the model $\left(F_{(7,124)}=\right.$ $15 \cdot 20 ; P=0 \cdot 00)$. There was no significant interaction between clue type and food category observed with regard to adjusted price $\left(F_{(7,124)}=1 \cdot 81 ; P=0 \cdot 09\right)$.
Finally, the ONQI scores of food items were not significant predictors of standardized price $\left(t_{(130)}=0 \cdot 49\right.$; $P=0 \cdot 62)$.

\section{Discussion}

The results of the present study indicate that the prices of more nutritious foods do not necessarily differ significantly from the prices of less nutritious foods in the same category. The results of analyses by food category indicate that, for some food categories, more nutritious foods do cost more but in others they cost less. After standardizing price comparisons according to weight (per $100 \mathrm{~g}$ ), prices of more nutritious breads, crackers and peanut butter were significantly higher than those of less nutritious items but the prices of more nutritious cereals were significantly lower. For cookies, cereal bars and juices, no significant price differences were found. Our findings suggest that, contrary to popular belief, choosing more nutritious foods within a food category may be possible in many instances without an increased financial burden for shoppers.

Previous research evaluating the cost of healthy foods has focused primarily on energy density and overall diet quality and has generally concluded that low-energydense diets high in nutritional quality tend to cost more than less nutritious, high-energy-dense diets ${ }^{(27-29)}$. Drewnowski and Specter ${ }^{(37)}$ identified an inverse relationship between the energy density and energy cost of foods and speculated that the association between poverty and diets high in energy-dense foods, such as refined grains, sugars and fat, may be mediated by the comparatively low cost of these foods. In another study, Drewnowski et $a l^{(27)}$ found the same association when considering the diets of French adults. Low-energy-dense diets were found to be higher in vitamins typically found in fruits and vegetables and lower in fat. These diets were also associated with higher diet costs. A study on diets of low-income women in California yielded similar results ${ }^{(29)}$. Despite these findings, there is some evidence that cost alone may not be an insurmountable obstacle to healthy eating. Raynor et al. ${ }^{(38)}$ found that adoption of a lower-energy, nutrient-dense diet did not increase dietary costs over time for families with obese children participating in a family-based treatment programme. Americans' attitudes about food costs and nutrition support the notion that prices influence behaviour. A large survey of US adults found that respondents rated the importance of food prices higher than the importance of nutrition when making food choices ${ }^{(39)}$. This finding suggests that individuals may sacrifice nutrition for monetary savings, choosing less-expensive foods regardless of their nutritional value. Alternatively, people may be more likely to purchase healthy foods when they cost less. In a study by Horgen et al. ${ }^{(40)}$, price decreases alone increased purchases 
of healthy food items in a restaurant, whereas health messages combined with price decreases did not. Irrespective of whether more healthy foods are more expensive, it is a common perception that they are ${ }^{(41,42)}$. This perception, real or hypothetical, may prevent many individuals from choosing healthy foods.

Whereas it has been clearly shown that higher-quality diets tend to cost more overall, it has not been shown that small improvements in food choices within food categories are not possible without increasing food prices. To our knowledge, no other study has investigated the price differences of foods within food categories. All foods lie on a nutritional continuum, ranging from highly nutritious to potentially harmful. It may be true that the nutritional value of cookies will pale in comparison with that of fresh produce; however, even cookies vary considerably in their composition and likelihood to improve or threaten health. Within the category of 'cookies', there exists a continuum in which cookies made with refined flour, trans fat and sugar lie on one end and those made with whole grains, unsaturated fats and fruit concentrates lie on the other. The results of the present study indicate that it is indeed possible to make better choices within food categories without increasing food prices. For example, simple substitutions such as replacing a 'fruit drink' largely comprised of added sugars with $100 \%$ juice or purchasing a wholegrain cereal instead of one made with refined grains may not affect the household grocery budget. Although these changes are small, they could conceivably add up to have a significant impact on the overall nutritional profile of the diet. However, most shoppers likely lack the knowledge required to identify the more nutritious offerings within diverse food categories. Programmes such as ND and/or programmes that offer in-store guidance ${ }^{(33,34)}$ that provide shoppers the capacity to readily and conveniently distinguish more from less nutritious food choices are much needed for the findings in the present study to be put to practical use.

The present study has a number of limitations. The sample of food items was not selected randomly, and therefore cannot be said to represent the population of all foods that shoppers have available to them. Thus, the present study tested the principle that more nutritious foods invariably cost more, and concluded that they do not; however, it does not show that they do not cost more on average. Furthermore, items were selected only from grocery stores accessible to researchers and in the geographical area of Jackson County, MO, USA. The prices of foods in these stores may not reflect the prices in stores in other areas of the country. We also used a relatively small sample, which limits the accuracy of the mean prices determined for each category. Because not all foods in each food category were classified as more nutritious or less nutritious, and the selection method was somewhat subjective, it is possible that other differences between the more and less nutritious foods selected could have influenced price.
The food categories used in the present study were only packaged foods and snack foods. We did not include other categories such as meat, dairy or produce, which may have greater cost differences between more and less nutritious choices. Although highly nutritious foods such as fresh produce are in general 'pricey', such foods call into question the very measure of food value. Historically, the value of food has been assessed in terms of energy per dollar. In an age of epidemic obesity, however, maximizing energy per dollar merely minimizes the cost of acquiring excess weight and increased risk of chronic disease. In contrast, maximizing the nutritional quality per dollar would reflect reductions in the cost of pursuing vitality, a far more desirable outcome. Objective measures of overall nutritional quality ${ }^{(33,34)}$ might be used for direct comparison of nutrition per dollar. The adoption of such a metric, arguably overdue, might well result in a very different determination about the economics of fruit and vegetable consumption.

It is also important to acknowledge that factors other than price, such as those related to culture ${ }^{(43)}$, personal preferences $^{(44)}$, values ${ }^{(45,46)}$ and social support ${ }^{(45,47)}$, may affect food purchasing decisions. Furthermore, price has varying effects on purchasing behaviour for different foods and beverages, depending on their specific price elasticities $^{(48)}$. Finally, even with all other factors supporting the healthier food choice, access to healthy foods may be limited $^{(44)}$. The 2010 US Department of Agriculture report on 'food deserts' describes the extent to which access to nutritious foods is limited in the USA ${ }^{(49)}$, a problem that is being actively targeted by the Obama administration, with a goal of eliminating food deserts within 7 years ${ }^{(50)}$.

Our findings do not imply that individuals at any income level can afford to eat a diet that is nutritious overall, nor do they imply that highly nutritious foods are not more costly on average than less nutritious foods. A minimum income level is likely required to ensure a diet that promotes good health ${ }^{(51)}$, with some categories of healthy foods, such as fruits and vegetables, still being out of reach for many. Nevertheless, the present study illustrates an important point: there are clearly many instances in which better food choices can be made without increasing cost. This is especially important for populations that have limited access to fresh fruit and vegetables because of financial or physical hindrances. However, this requires that shoppers be able to distinguish more from less nutritious foods within given categories. Interventions to foster this ability as the norm among shoppers are clearly warranted, as is further study of nutrition economics and ways to improve diet while controlling food costs.

\section{Acknowledgements}

The source of funding for the present study was through a grant obtained from the Independence Missouri School District. The authors have no conflict of interest related to 
the present study, and no party with a financial interest of any kind in the study or its outcome was involved in study implementation, data collection, data analysis or interpretation. D.L.K. contributed to the design and oversight and critical review of the study; K.D. drafted the manuscript; V.N. contributed to the data analysis, critical review and editing of the manuscript; J.R. analysed the data; J.W. and E.S. helped in implementation of the study; C.K. designed the study and did the final editing. The authors acknowledge the technical assistance of Mrs Michelle Evans.

\section{References}

1. World Health Organization (2000) Obesity: Preventing and Managing the Global Epidemic. Report of a WHO Consultation on Obesity. WHO Technical Report Series no. 894. Geneva: WHO.

2. Abbott RD, Behrens GR, Sharp DS et al. (1994) Body mass index and thromboembolic stroke in nonsmoking men in older middle age. The Honolulu Heart Program. Stroke 25, 2370-2376.

3. Arcaro G, Zamboni M, Rossi L et al. (1999) Body fat distribution predicts the degree of endothelial dysfunction in uncomplicated obesity. Int J Obes Relat Metab Disord 23, 936-942.

4. Kortelainen ML (2002) Myocardial infarction and coronary pathology in severely obese people examined at autopsy. Int J Obes Relat Metab Disord 26, 73-79.

5. Lang IA, Llewellyn DJ, Alexander K et al. (2008) Obesity, physical function, and mortality in older adults. $J \mathrm{Am}$ Geriatr Soc 56, 1474-1478.

6. Poirier P, Giles TD, Bray GA et al. (2006) Obesity and cardiovascular disease: pathophysiology, evaluation, and effect of weight loss: an update of the 1997 American Heart Association Scientific Statement on Obesity and Heart Disease from the Obesity Committee of the Council on Nutrition, Physical Activity, and Metabolism. Circulation 113, 898-918.

7. Rhoads GG \& Kagan A (1983) The relation of coronary disease, stroke, and mortality to weight in youth and in middle age. Lancet 1, 492-495.

8. Shinton R, Shipley M \& Rose G (1991) Overweight and stroke in the Whitehall study. J Epidemiol Community Health 45, 138-142.

9. Stamler R, Stamler J, Riedlinger WF et al. (1978) Weight and blood pressure. Findings in hypertension screening of 1 million Americans. JAMA 240, 1607-1610.

10. McMillan-Price J, Petocz P, Atkinson F et al. (2006) Comparison of 4 diets of varying glycemic load on weight loss and cardiovascular risk reduction in overweight and obese young adults: a randomized controlled trial. Arch Intern Med 166, 1466-1475.

11. Thomas DE, Elliott EJ \& Baur L (2007) Low glycaemic index or low glycaemic load diets for overweight and obesity. Cochrane Database Syst Rev, issue 3, CD005105. http://onlinelibrary. wiley.com/o/cochrane/clsysrev/articles/CD005105/frame.html

12. Davis JN, Alexander KE, Ventura EE et al. (2009) Inverse relation between dietary fiber intake and visceral adiposity in overweight Latino youth. Am J Clin Nutr 90, 1160-1166.

13. Harding AH, Wareham NJ, Bingham SA et al. (2008) Plasma vitamin $\mathrm{C}$ level, fruit and vegetable consumption, and the risk of new-onset type 2 diabetes mellitus: the European Prospective Investigation of Cancer - Norfolk Prospective Study. Arch Intern Med 168, 1493-1499.

14. Lee JE, Giovannucci E, Smith-Warner SA et al. (2006) Intakes of fruits, vegetables, vitamins $\mathrm{A}, \mathrm{C}$, and $\mathrm{E}$, and carotenoids and risk of renal cell cancer. Cancer Epidemiol Biomarkers Prev 15, 2445-2452.

15. Lopez EP, Rice C, Weddle DO et al. (2008) The relationship among cardiovascular risk factors, diet patterns, alcohol consumption, and ethnicity among women aged 50 years and older. J Am Diet Assoc 108, 248-256.

16. Laaksonen DE, Laukkanen JA, Niskanen L et al. (2004) Serum linoleic and total polyunsaturated fatty acids in relation to prostate and other cancers: a population-based cohort study. Int J Cancer 111, 444-450.

17. Laaksonen DE, Nyyssonen K, Niskanen L et al. (2005) Prediction of cardiovascular mortality in middle-aged men by dietary and serum linoleic and polyunsaturated fatty acids. Arch Intern Med 165, 193-199.

18. Quatromoni PA, Pencina M, Cobain MR et al. (2006) Dietary quality predicts adult weight gain: findings from the Framingham Offspring Study. Obesity (Silver Spring) 14, 1383-1391.

19. Warensjo E, Sundstrom J, Vessby B et al. (2008) Markers of dietary fat quality and fatty acid desaturation as predictors of total and cardiovascular mortality: a population-based prospective study. Am J Clin Nutr 88, 203-209.

20. Yang EJ, Chung HK, Kim WY et al. (2003) Carbohydrate intake is associated with diet quality and risk factors for cardiovascular disease in U.S. adults: NHANES III. J Am Coll Nutr 22, 71-79.

21. Appel LJ, Moore TJ, Obarzanek E et al. (1997) A clinical trial of the effects of dietary patterns on blood pressure. DASH Collaborative Research Group. N Engl J Med 336, 1117-1124.

22. Fogli-Cawley JJ, Dwyer JT, Saltzman E et al. (2007) The 2005 Dietary Guidelines for Americans and risk of the metabolic syndrome. Am J Clin Nutr 86, 1193-1201.

23. Fung TT, Willett WC, Stampfer MJ et al. (2001) Dietary patterns and the risk of coronary heart disease in women. Arch Intern Med 161, 1857-1862.

24. Krebs-Smith SM \& Kris-Etherton P (2007) How does MyPyramid compare to other population-based recommendations for controlling chronic disease? J Am Diet Assoc 107, 830-837.

25. Dietz WH (2004) Overweight in childhood and adolescence. $N$ Engl J Med 350, 855-857.

26. Ogden CL, Carroll MD, Curtin LR et al. (2006) Prevalence of overweight and obesity in the United States, 1999-2004. JAMA 295, 1549-1555.

27. Drewnowski A, Monsivais P, Maillot M et al. (2007) Lowenergy-density diets are associated with higher diet quality and higher diet costs in French adults. J Am Diet Assoc 107, 1028-1032.

28. Drewnowski A (2004) Obesity and the food environment: dietary energy density and diet costs. Am J Prev Med 27, Suppl. 3, S154-S162.

29. Townsend MS, Aaron GJ, Monsivais P et al. (2009) Lessenergy-dense diets of low-income women in California are associated with higher energy-adjusted diet costs. Am J Clin Nutr 89, 1220-1226.

30. Katz D (2006) School Nutrition Programs: Nutrition Detectives. http://www.davidkatzmd.com/nutritiondetectives.aspx

31. Katz DL, Michael J, Treu J et al. (2011) Teaching healthful food choices to elementary school students and their parents: the Nutrition Detectives ${ }^{\mathrm{TM}}$ program. $J$ Sch Health 81, 21-28.

32. NuVal L (2009) Origins and development. http://www.nuval. com/Science/origins

33. Katz DL, Njike VN, Faridi Z et al. (2009) The stratification of foods on the basis of overall nutritional quality: the Overall Nutritional Quality Index (ONQI). Am J Health Promot 24, 133-143.

34. Katz DL, Njike VY, Faridi Z et al. (2009) The stratification of foods on the basis of overall nutritional quality: the overall nutritional quality index. Am J Health Promot 24, 133-143. 
35. Katz DL, Njike VY, Rhee LQ et al. (2010) Performance characteristics of NuVal and the Overall Nutritional Quality Index (ONQI). Am J Clin Nutr 91, Suppl. 4, S1102-S1108.

36. Chiuve SE, Sampson L \& Willett WC (2010) Do nutrition rating systems promote a healthy diet? An evaluation of the Overall Nutritional Quality Index (ONQI) and risk of chronic disease. FASEB J 24, meeting Abstract Suppl., lb383.

37. Drewnowski A \& Specter SE (2004) Poverty and obesity: the role of energy density and energy costs. Am J Clin Nutr 79, 6-16.

38. Raynor HA, Kilanowski CK, Esterlis I et al. (2002) A costanalysis of adopting a healthful diet in a family-based obesity treatment program. J Am Diet Assoc 102, 645-656.

39. Glanz K, Basil M, Maibach E et al. (1998) Why Americans eat what they do: taste, nutrition, cost, convenience, and weight control concerns as influences on food consumption. J Am Diet Assoc 98, 1118-1126.

40. Horgen KB \& Brownell KD (2002) Comparison of price change and health message interventions in promoting healthy food choices. Health Psychol 21, 505-512.

41. Lappalainen R, Saba A, Holm L et al. (1997) Difficulties in trying to eat healthier: descriptive analysis of perceived barriers for healthy eating. Eur J Clin Nutr 51, Suppl. 2, S36-S40.

42. Lloyd HM, Paisley CM \& Mela DJ (1995) Barriers to the adoption of reduced-fat diets in a UK population. J Am Diet Assoc 95, 316-322.

43. Sealy YM (2010) Parents' food choices: obesity among minority parents and children. Community Health Nurs 27, $1-11$.
44. Wiig K \& Smith C (2009) The art of grocery shopping on a food stamp budget: factors influencing the food choices of low-income women as they try to make ends meet. Public Health Nutr 12, 1726-1734.

45. Lawrence W \& Barker M (2009) A review of factors affecting the food choices of disadvantaged women. Proc Nutr Soc 68, 189-194.

46. Inglis V, Ball K \& Crawford D (2005) Why do women of low socioeconomic status have poorer dietary behaviours than women of higher socioeconomic status? A qualitative exploration. Appetite 45, 334-343.

47. Watt RG, Tull KI, Hardy R et al. (2009) Effectiveness of a social support intervention on infant feeding practices: randomised controlled trial. J Epidemiol Community Health 63, 156-162.

48. Andreyeva T, Long MW \& Brownell KD (2010) The impact of food prices on consumption: a systematic review of research on the price elasticity of demand for food. $A m \mathrm{~J}$ Public Health 100, 216-222.

49. US Department of Agriculture (2009) Access to Affordable and Nutritious Food: Measuring and Understanding Food Deserts and Their Consequences. Report to Congress. http://www.ers.usda.gov/Publications/AP/AP036/AP036fm.pdf

50. US Department of Agriculture (2010) Obama administration details healthy food financing initiative. http://www. hhs.gov/news/press/2010pres/02/20100219a.html

51. Dowler E (2010) Income needed to achieve a minimum standard of living. BMJ 341, c4070. 